\title{
Carious Nasal Tooth: A Case Report from the Oral and Maxillofacial Unit of Komfo Anokye Teaching Hospital
}

\author{
Alexander Acheampong Oti ${ }^{*}$, Sabbah Daniel Kwasi², Siale Edem Edward ${ }^{2}$, \\ Gyimah Nana Tuffor Ampem² \\ ${ }^{1}$ Kwame Nkrumah University of Science and Technology Dental School, Kumasi, Ghana \\ ${ }^{2}$ Komfo Anokye Teaching Hospital, Kumasi, Ghana \\ Email: aotiacheampong@yahoo.com
}

Received 20 April 2014; revised 3 June 2014; accepted 19 June 2014

Copyright (C) 2014 by authors and Scientific Research Publishing Inc.

This work is licensed under the Creative Commons Attribution International License (CC BY). http://creativecommons.org/licenses/by/4.0/

(c) (i) Open Access

\begin{abstract}
Ectopic teeth erupting in the nasal cavity are a rare occurrence. This may present with varying degree of morbidity. We present a very rare occurrence case report of an ectopic carious tooth in a nasal cavity. The upper left central incisor was congenitally missing and patient thought it was a form of diastema. Her chief complaint was painful whitish growth in the floor of her left nose with foul smelling mucoid discharge. The learning experience in this case report is that, in conducting examination for a missing upper incisors, the floor of the nose must be included. A further research is needed to establish the actual pathogenesis involved in cariogenesis in the nasal cavity.
\end{abstract}

\section{Keywords}

Ectopic, Tooth, Nasal Cavity, Caries

\section{Introduction}

Tooth eruption is a process whereby the developing tooth migrates from its intraosseous location in the jaw to its functional position within the oral cavity. A variety of problems with eruption may arise during this transitional dentition phase and one such problem is ectopic eruption.

An ectopic eruption is a disturbance in which the tooth does not follow its usual course and erupts in an abnormal position [1]. The ectopic eruption of teeth in non-dental sites is a rare phenomenon [2].

Ectopic teeth have been observed in the palate [2] and maxillary sinus [3] [4]. They have also been reported in

${ }^{*}$ Corresponding author.

How to cite this paper: Oti, A.A., Kwasi, S.D., Edward, S.E. and Ampem G.N.T. (2014) Carious Nasal Tooth: A Case Report from the Oral and Maxillofacial Unit of Komfo Anokye Teaching Hospital. Open Journal of Stomatology, 4, 310-313.

http://dx.doi.org/10.4236/ojst.2014.46044 
the nasal cavity, orbit, mandibular condyle [5] and ovarian teratoma [6].

Intranasal teeth are particularly rare, and can be supernumerary, deciduous, or permanent. Supernumerary teeth occur more commonly intranasally than deciduous or permanent teeth [7].

The aetiology of ectopic nasal teeth remains obscure, although many different explanations exist, including developmental disturbances, such as cleft palate; teeth displaced by trauma or cysts; displacement of a developing tooth secondary to a maxillary infection, either odontogenic or rhinogenic; hereditary factors, including Gardner's syndrome and cleidocranial dysostosis; obstruction of downward eruption secondary to crowding of dentition, persistent deciduous teeth, or exceptionally dense bone; and the root of an unusually long tooth projecting into the nose [8].

Smith et al. [7], in a review of the world literature on nasal teeth, identified 17 supernumerary teeth from a total of 27 well documented intranasal teeth cases.

Nasal teeth may present with symptoms such as nasal discharge, nasal or facial pain, necrotic or granulation tissue around the suspected tooth amongst others. They may be completely asymptomatic and may be noticed as incidental findings on $\mathrm{x}$-rays.

The diagnosis of nasal teeth is made on the basis of clinical and radiographic findings. Various imaging techniques have been employed including the use of CT scans [2] and panoramic radiography [8]. Clinically, an intranasal tooth may be seen as a white mass in the nasal cavity surrounded by granulation tissue and debris. Radiographically, the nasal teeth may appear as radiopaque lesions with the same attenuation as that of the oral teeth.

Removal of an intranasal tooth is the main treatment modality employed by majority of individuals with the aim of alleviating symptoms and preventing complications. The endoscopic approach has been employed by some authors [9].

\section{Case Report}

We present a 32-year-old lady from Kumasi in the Ashanti Region, and a hair dresser by profession. She complained of a whitish solid growth in her left nostril which had been progressively increasing in size. The swelling was associated with nasal irritation, an offensive mucoid discharge as well as occasional pain for duration of 4 weeks. On extra-oral examination, there was no facial asymmetry or palpable lymph nodes.

Intra-oral examination revealed that all teeth were present except tooth 21 (Figure 1). No carious lesions were observed in the teeth present. There was no previous history of trauma or tooth extraction during childhood.

Examination of the nose revealed that the left nostril contained a whitish solid mass protruding from the floor of the nose (Figure 2). The mass was surrounded by granulation tissue and mucus. The mass was hard in consistency and looked similar to the crown of an incisor. Interestingly, there was an obvious carious lesion on portions of the crown of the tooth. An initial impression of a nasal ectopic tooth was made. Radiographic imaging (OPG), showed a missing tooth 21 and a radiopaque substance in the floor of the nose.

An extraction of the nasal tooth was carried out under local anaesthesia. The extracted tooth appeared to be a smaller than normal central incisor which had a dilacerated root (Figure 3). An explorer was used to determine the depth of the carious lesion and this showed that the carious lesion was in the dentine of the tooth.

There was complete disappearance of presenting symptoms after the extraction and the patient is doing well now.

\section{Discussion}

Intranasal teeth are particularly rare, and can be supernumerary, deciduous, or permanent. Supernumerary teeth occur more commonly intranasally than deciduous or permanent teeth [7].

The aetiology of ectopic nasal teeth remains not clear, although many different explanations exist, including developmental disturbances, such as cleft lip and palate; teeth displaced by trauma or cysts; displacement of a developing tooth secondary to a maxillary infection, either odontogenic or rhinogenic; hereditary factors, including Gardner's syndrome and cleidocranial dysostosis; obstruction of downward eruption secondary to crowding of dentition, persistent deciduous teeth, or exceptionally dense bone; and the root of an unusually long tooth projecting into the nose [2] [7]. But in the current case the patient could not confirm any evidence of trauma, extraction or infection to the site. All she could confirm was that she has never had the upper left central incisor. 


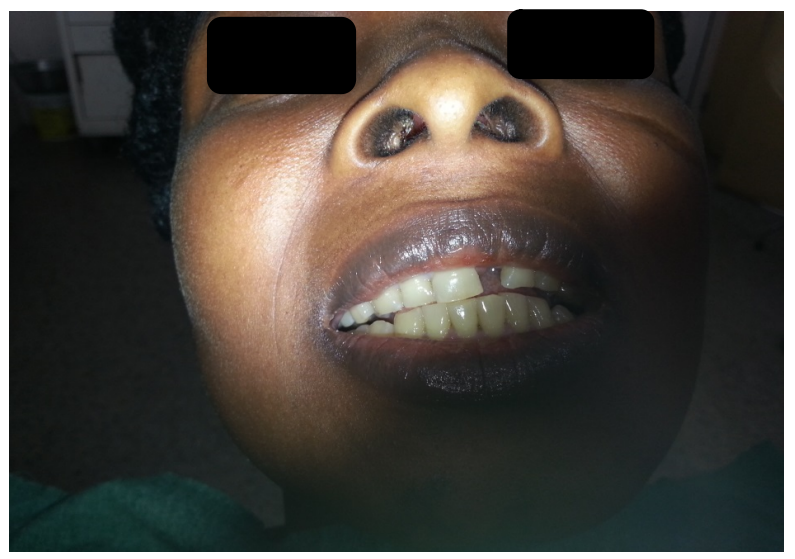

Figure 1. Picture showing missing left central incisor.

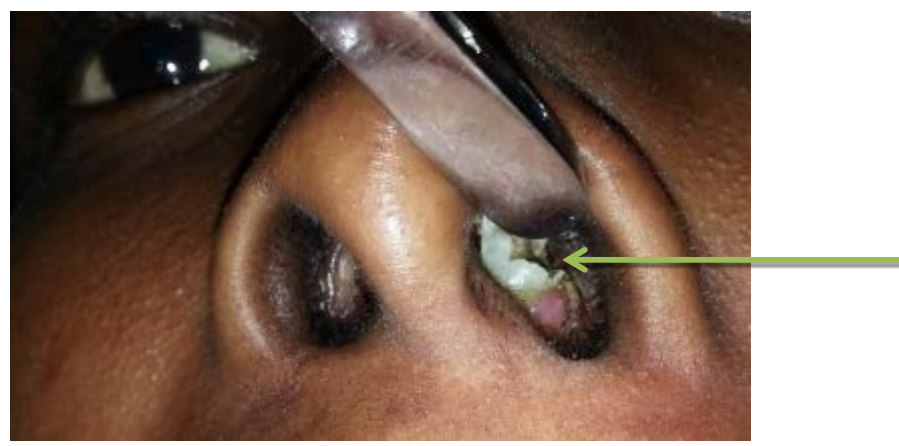

Carious ectopic tooth

Figure 2. Picture showing carious ectopic tooth.

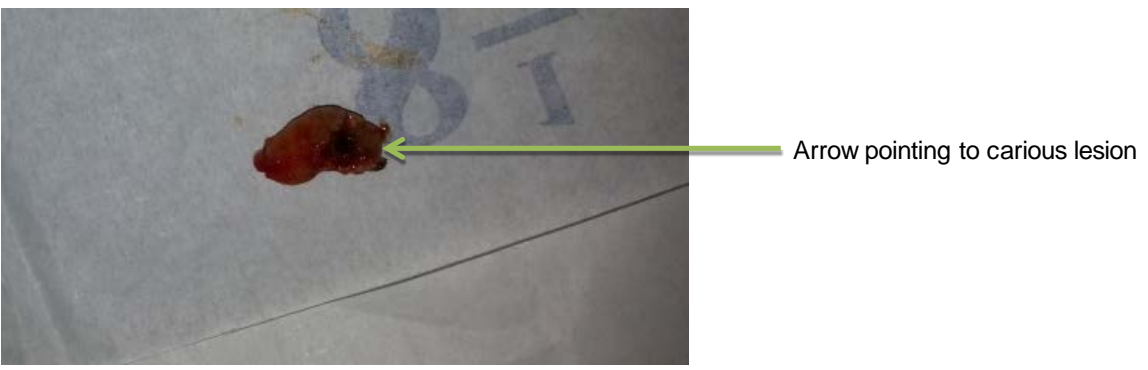

Figure 3. Picture showing the carious extracted tooth.

If symptomatic, the clinical manifestations of ectopic teeth in the nasal cavity are varied and can include unilateral nasal obstruction, epistaxis, chronic nasal discharge, facial pain and headache, chronic localized ulceration, necrotic or granulation tissue in the nasal cavity, a rhinolith and signs of paranasal sinusitis [1]-[3] [7] [8] [10]. In this present case, she complained of a whitish solid growth in her left nostril which had been progressively increasing in size. The swelling was associated with nasal irritation, offensive mucoid discharge as well as occasional pain in the left nasal floor.

The diagnosis of nasal teeth is made on the basis of clinical and radiographic findings. Clinically, an intranasal tooth may be seen as a white mass in the nasal cavity surrounded by granulation tissue and debris [7]. Radio graphically, the nasal teeth in our patients appeared as radiopaque lesions with the same attenuation as that of the oral teeth.

The pain complaint by the patient in the left nostrils could be as a result of the carious or ectopic tooth. During our literature review of ectopic nasal tooth, there was no case of a carious nasal tooth. The possible explanation for this phenomenon could come from the fact that, the ectopic tooth crown was partly surrounded by mucous and granulation tissue. According to a recent study, the nosterils of health adults harbours microorganisms 
similar to the oral cavity. These organisms include staphylococcus aureus and other organisms which are known cariogenic organisms [11] [12].

In a study of thebacterialflora of the nose and nasopharynx in 86 healthy young men. Common pathogens (Haemophilus influenzae and Streptococcus pneumoniae) were isolated from only 6\% of all 172 nasal cavities. The same pathogens were isolated from $27 \%$ of 86 nasopharyngeal samples. H. influenzae dominated over S. pneumoniae both in the nose and the nasopharynx [12].

In addition to the above microorganism, the human nasal mucous is known to be composed of fermentable carbohydrate [13]. The possible pathogenesis could be that, the presence of the carbohydrate could be a source of substrate for the microorganisms for the production of acid to cause demineralization of the crown of the ectopic tooth in the nostrils.

The main treatment of nasal tooth is by extraction which could either be under local or general anaesthesia. In this case, the extraction was done using upper anterior forcep and the use of rotational force to the tooth.

\section{Limitation}

The major limitation in this presentation is that, at the time of writing this report, the x-ray of the patient was not available to serve as additional evidence to support the presence of an ectopic nasal tooth.

\section{Conclusion}

Ectopic permanent nasal tooth is very rare. The nasal microbiology and the presence of nasal mucous may be enough to cause tooth decay to an ectopic tooth in the nasal cavity. The learning experience in this case report is that, in conducting examination for a missing upper incisors, the floor of the nose must be included. A further research is needed to establish the actual pathogenesis involved in cariogenesis in the nasal cavity.

\section{References}

[1] Yaseen, S.M., Naik, S. and Uloopi, K.S. (2011) Ectopic Eruption-A Review and Case Report. Contemporary Clinical Dentistry, 2, 3-7.

[2] Chen, A., Huang, J.-K., Cheng, S.-J. and Sheu, C.-Y. (2002) Nasal Teeth: Report of Three Cases. AJNR Am J Neuroradiol, 23, 671-673.

[3] Alexandrakis, G., Hubbell, R.N. and Aitken, P.A. (2000) Nasolacrimal Duct Obstruction Secondary to Ectopic Teeth. Ophthalmology, 107, 189-192.

[4] Elango, S. and Palaniappan, S.P. (1991) Ectopic Tooth in the Roof of the Maxillary Sinus. Ear Nose Throat J., 70, 365-366.

[5] Iglesias-Martin, F., Infante-Cossio, P., Torres-Carranza, E., Prats-Golczer, V.-E. and Garcia-Perla-Garcia, A. (2012) Ectopic Third Molar in the Mandibular Condyle: A Review of the Literature. Medicina Oral Patologia Oral y Cirugia Bucal, 17, E1013-E1017.

[6] Ingale, Y., Shankar, A.A., Routray, S., Agrawal, M., Kadam, A. and Patil, T. (2013) Ectopic Teeth in Ovarian Teratoma: A Rare Appearance. Case Reports in Dentistry, 2013, Article ID: 970464.

[7] Smith, R.A., Gordon, N.C. and De Luchi, S.F. (1979) Intranasal Teeth. Report of Two Cases and Review of the Literature. Oral Surgery, Oral Medicine, and Oral Pathology, 47, 120-122.

[8] Choi, J.W., Park, H.S., Park, B.S. and Koo, S.K. (2011) Ectopic Eruption of a Tooth into the Nasal Cavity with Sinusitis: A Case Report. Ournal Rhinol, 68-70.

[9] Ricks, R.G. and Shaaban, A, (2012) Nasal Tooth: An Unusual Cause of Nasal Obstruction and Sinusitis. BMJ Case Reports, 2012.

[10] Pracy, J.P., Williams, H.O. and Montgomery, P.Q. (1992) Nasal Teeth. J Laryngol Otol., 106, 366-367.

[11] Otsuka, H., Takanashi, M. and Okubo, K. (2013) [Analysis of Bacterial Culture and Cytology in Nasal Smear of Japanese Ceder Pollinosis in Pre-Season and in Season]. Arerugī Allergy, 62, 689-697.

[12] Ylikoski, J., Savolainen, S. and Jousimies-Somer, H. (1989) Bacterial Flora in the Nasopharynx and Nasal Cavity of Healthy Young Men. Journal for Oto-Rhino-Laryngology, Head and Neck Surgery, 51, 50-55. http://dx.doi.org/10.1159/000276031

[13] Gheri, G., Bryk, S.G., Sgambati, E. (1993) Light Microscopic Histochemical Detection of Sugar Residues of Glycoconjugates in Human Nasal Mucosa Using HRP-Lectins. Eur J Histochem, 37, 345-352. 
Scientific Research Publishing (SCIRP) is one of the largest Open Access journal publishers. It is currently publishing more than 200 open access, online, peer-reviewed journals covering a wide range of academic disciplines. SCIRP serves the worldwide academic communities and contributes to the progress and application of science with its publication.

Other selected journals from SCIRP are listed as below. Submit your manuscript to us via either submit@scirp.org or Online Submission Portal.
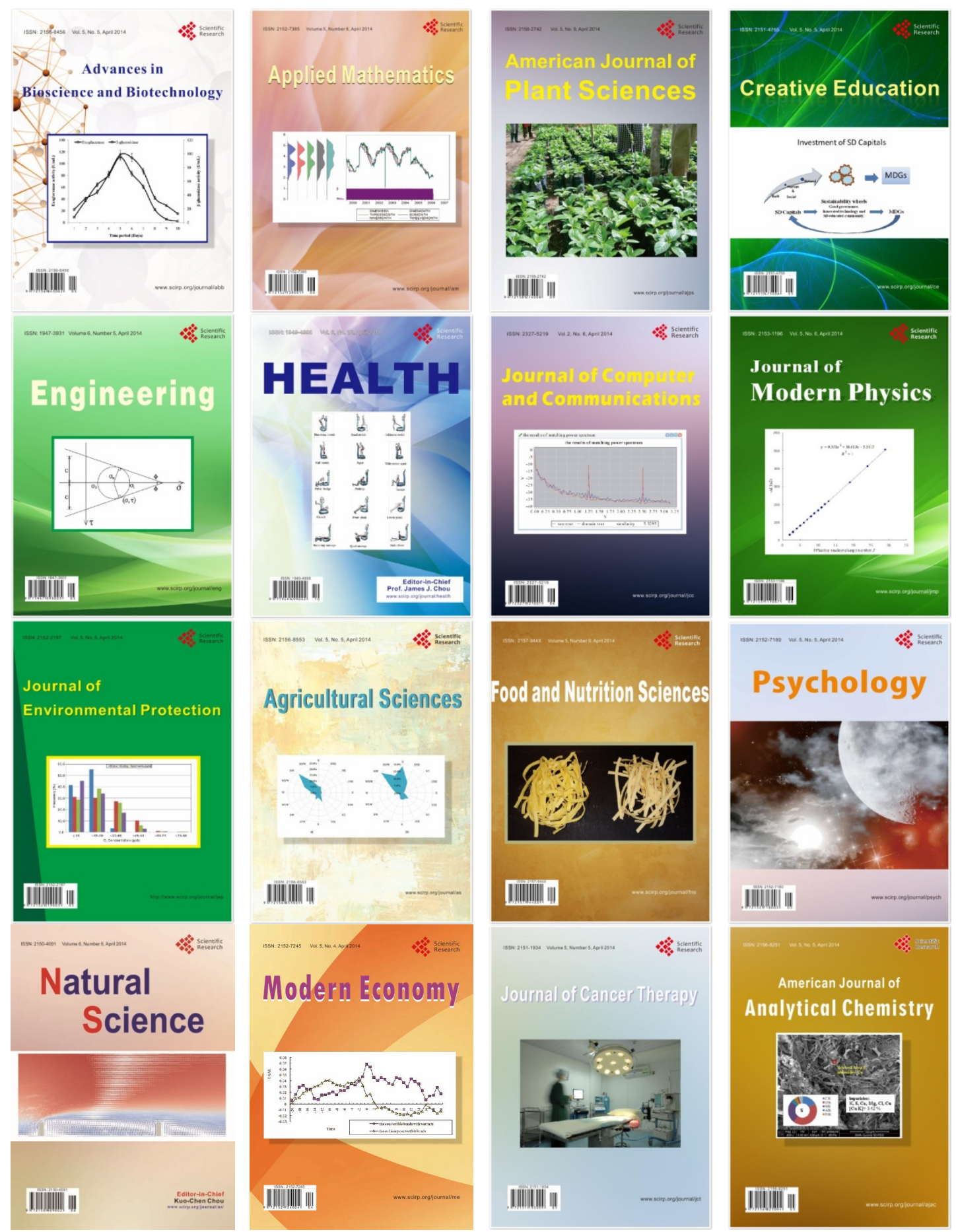